Egyptian Journal of Rabbit Science, 23 (2): 149 - 160(2013)

\title{
EFFECT OF ROYAL JELLY IN HONEY-INCLUDED EGG YOLK BASED EXTENDERS ON MOTILITY, VIABILITY AND FERTILIZING ABILITY OF FROZEN RABBIT SPERMATOZOA
}

\author{
A.M. El-Sherbiny \\ Animal Production Department., Faculty of Agriculture, Ain Shams \\ University, Cairo, Egypt
}

The present study was designed to investigate the efficacy of Royal Jelly $(R J)$ addition in honey-included egg yolk and Tris-citricglucose with dimethysulfoxide (DMSO) for the extension of New Zealand White (NZW) rabbit buck semen conserved frozen. Fifteen sexually mature NZW rabbit bucks, aged 17 months with average body weight of $3.9 \mathrm{~kg}$, were selected for high quality semen. One hundred and forty hybrid nonporous NZW rabbit does, were used for artificial insemination (20 does per each experimental group).

Semen was collected from rabbit bucks, pooled and diluted with 8 different extenders. Control group had Tris-citric-glucose + DMSO + $20 \%$ egg yolk, while the other 7 experimental extenders were based on Tris-citric-glucose with DMSO, 2\% pure bee honey and $18 \%$ egg yolk which were added to diluents $(v / v)$. Royal jelly $(R J)$ was added in increasing concentrations of 0,10, 20, 30, 40, 50 and $100 \mathrm{mg} / 6 \mathrm{ml}$ diluents for extenders 1, 2, 3, 4, 5, 6 and 7, respectively. Evaluations for percentages of progressive motility, dead and abnormal spermatozoa were done immediately after dilution and one month of freezing in liquid nitrogen. Fertilizing ability was evaluated as pregnancy rate and litter size of 20 does inseminated artificially for each extender, which showed $\geq 50 \%$ sperm progressive motility after thawing. Extender contained 10 $\mathrm{mg} R \mathrm{JJ} 6 \mathrm{ml}$ diluent showed the best values for motility, dead and abnormal spermatozoa, also for pregnancy rate and litter size.

Conclusively, the results of the present study proved that the addition of royal jelly in bee honey-included egg yolk based extenders may improve the motility, viability and fertilizing ability of rabbit spermatozoa. However, the effect of RJ on NZW rabbit semen quality and fertility is concentration dependent.

Key words: Honey, egg yolk, extenders, motility, fertilizing ability, rabbit, royal jelly, semen. 
Royal jelly $(\mathrm{RJ})$ is a secretion product of the cephalic glands of nurse bees that has been used for centuries for its extraordinary properties and health effects (Pavel et al., 2011). Royal jelly is one of the most studied bee products, but there still remains much to reveal about its biochemistry and biological activity in future research. On the other hand, the chemistry and bioactive compounds of RJ are not sufficiently known. Due to its complex composition, RJ has a multitude of pharmacological activities (Mărghitas, 2008). On the other hand, RJ is collected and sold as a dietary supplement, claiming various health benefits because of components like B-complex vitamins such as pantothenic acid (vitamin $\mathrm{B}_{5}$ ) and pyridoxine (vitamin $\mathrm{B}_{6}$ ). The overall composition of $\mathrm{RJ}$ is $67 \%$ water, $12.5 \%$ crude protein (including small amounts of many different amino acids) and $11 \%$ simple sugars (monosaccarides), also including a relatively high amount $(5 \%)$ of fatty acids. It also contains many trace minerals, some enzymes, antibacterial and antibiotic components, and trace amounts of vitamin C. However, vitamins A, $\mathrm{D}, \mathrm{E}$ and $\mathrm{K}$ are completely absent from RJ (Graham, 1992). RJ has immunemodulatory activities (Gasic et al., 2007).

Sperm cryopreservation is a great challenge, since many sperms are irreversibly damaged or present altered functionality after the whole process (Mocé and Vincente, 2009). The possible roles of cryoprotectants and additives are considered in the context of their putative interactions with the sperm plasma membrane (Holt, 2000). Dimethylsulfoxide (DMSO) as a cryoprotectant in egg yolk diluents of ejaculated NZW rabbits semen used for improving cryopreservation method (Kashiwazaki et al., 2006).Many investigators studied the effect of royal jelly on male fertility. On rats, Hassan (2009) studied the efficiency of treating the adult male rats with royal jelly in drinking water on sexual efficiency. He concluded that, royal jelly is a beneficial treatment of male rats especially on sperm count and livability. Yang et al. (2012), studied the influence of RJ on the reproductive function of pubertal male rats, and concluded that high-dose of oral royal jelly administration for 4 weeks adversely affected the reproductive system of pubescent male rats, but the unfavorable effects are alleviated to some extent by cessation of administration. On rabbits, Elnagar (2010) concluded that RJ administration to heat stressed male rabbits can counteract their "summer infertility" and improve their physiological status and also for growing rabbits (Elnagar et al., 2010). On buffalo, in vitro study by Abd-Allah (2012)showed the effect of RJ on the fertilizing ability of buffalo spermatozoa and suggested that treating buffalo sperm with $0.4 \% \mathrm{RJ}$ in combination with heparin is 
effective not only to induce sperm acrosome reaction but also is effective for in vitro fertilizing capacity of the cryopreserved buffalo spermatozoa.

Royal jelly is safe and effective in the treatment of male infertility; after three months of treatment infertile men with RJ increased significantly sperm active motility and sperm concentration (Al-Sanafi et al., 2007).

Further experimentation (in vitro, in animal's research) and validation would be needed to prove any useful benefit and action mechanism of native $\mathrm{RJ}$ and isolated compounds as well. Data on adding RJ to rabbit semen extenders are not available in the reviewed literature.

Therefore, the aim of the present work is to study the effect of royal jelly addition to pure bee honey with egg yolk based extender on motility, viability, abnormalities and fertilizing ability of NZW rabbit semen stored in liquid nitrogen.

\section{MATERIALS AND METHODS}

The present study was carried out during winter season, 2012/2013 (December 2012, January 2013 and February 2013) at the Intensive Rabbit Production Unit, Faculty of Agriculture, Ain Shams University, Cairo, Egypt. Among seasons of the year in Egypt, winter season- with average air temperature and relative humidity of $15^{\circ} \mathrm{C}$ and $76 \%$, respectively- showed good semen quality (El-Sherbiny, 1987).

\section{Experimental animals:}

Fifteen sexually mature New Zealand White rabbit bucks, aged 17 months with average body weight $3.9 \mathrm{~kg}$, were selected for high quality semen ( reaction time $<2$ minutes, color white only, volume $\geq 0.2 \mathrm{ml}$, density creamy and milky only, concentration $>60$ million $/ \mathrm{ml}$ semen, deadsperm percentage $<20 \%$, and sperm abnormalities $<20 \%$ ). For testing the fertilizing ability of frozen diluted semen, 140 hybrid nonporous-females at a Private Rabbit Farm, Kalioubia, Egypt, were used in the experiment (20 females per each experimental group). All experimental animals were housed individually in flat deck cages and fed a commercial concentrate pelleted diet according to their reproductive condition according to NRC (1977) and fresh water was provided ad libitum.

\section{Semen collection and evaluation:}

Semen was collected from each buck twice weekly using an artificial vagina. Two female rabbits were used as a teaser. Immediately after semen 
collection, gel plug was removed. Only ejaculates with white color and good mass motility ( $\geq 3$ on a $0-5$ scale) were used for semen manipulation. Then, semen from ten bucks was pooled together as described by Safaa et al. (2012). The parameters were examined to evaluate semen quality of rabbit bucks as described by El-Sherbiny (1987) and Madhuri et al. (2012). Pooled semen was diluted by adding one volume semen to five volume extender at $37^{\circ} \mathrm{C}$.

Percentages of sperm motility, dead and total abnormalities of spermatozoa were evaluated immediately after semen extension, and one month later after conservation in liquid nitrogen. All data registered for these physical semen characteristics were done in triplicates.

\section{Semen dilution:}

Tris-citric-glucose with $1.75 \mathrm{M}$ DMSO, as described by Vincente and Viudes-de-Castro (1996) was used in the present study. Tris-citric-glucose was the basic diluent and had the following composition: $0.25 \mathrm{M}$ of Tris buffer (hydroxylmethyl) aminomethan, $0.87 \mathrm{M}$ of citric acid monohydrate, $0.47 \mathrm{M}$ $\mathrm{D}(+)$ glucose, 100000 IU penicillin and 100mg streptomycin sulfate (Viudesde-Castro and Vicent, 1996 and Si et al., 2006), All previous components were dissolved in glass bid stilled water and completed total volume to $100 \mathrm{ml}$.

Unpublished data revealed that addition of bee honey in concentrations of 2 and 3\%honey toegg yolk with Tris-citric-glucose + DMSO diluents showed that the best values for motility, livability and abnormalities, also for pregnancy rate and litter size after thawing. A preliminary work was done and demonstrated that addition of $2 \%$ honey to the previous extender showed the best results than addition of 3\% honey. In the present study, the diluent used contained Tris-citic-glucose + DMSO $+18 \%$ egg yolk $+2 \%$ bee honey.

Semen was collected from fifteen sexually mature NZW rabbit bucks (720 ejaculates were used in the present study), pooled and diluted with 8 different extenders. Control group had Tris-citric-glucose + DMSO + 20\% egg yolk. While the other 7 experimental extenders were based on Tris-citricglucose with DMSO, $2 \%$ pure bee honey and $18 \%$ egg yolk which were added to diluents $(\mathrm{v} / \mathrm{v})$. Royal jelly $(\mathrm{RJ})$ was added in increasing concentrations of 0 , 10, 20, 30, 40, 50 and $100 \mathrm{mg} / 6 \mathrm{ml}$ diluents for extenders 1, 2, 3, 4, 5, 6 and 7, respectively.

\section{Semen freezing:}

Semen freezing was performed with RJ and honey-included egg yolk extenders as described by Mocé and Vincente (2009). Semen freezing was 
performed with extenders as follows: Directly after semen dilution, diluted semen vials was kept in a glass of water at $37^{\circ} \mathrm{C}$, so that diluted semen level in vials kept below the surface of water; then, quickly the vials of diluted semen were transferred in a refrigerator to be cooled down to $+5^{\circ} \mathrm{C}$. Extended semen was left at $5^{\circ} \mathrm{C}$ for $45-60$ minutes. Vials were stirred well by applying a rotative motion before backing. The extended semen was sucked immediately into $0.5 \mathrm{ml}$ cooled French straws. The straws were filled incompletely so that a column of air $0.5-1 \mathrm{~cm}$ in length was left in each straw. The straws were then plugged by pressing their free end into a $1 / 2 \mathrm{~cm}$ thick layer of polyvinyl alcohol powder. The plugged straws were put into a glass of water maintained at $4-5^{\circ} \mathrm{C}$ to remove excess of powder and to ensure good plugs.

After the completion of packing, the straws were removed from the water glass and placed in a horizontal position into a special cooled rack; then, the rack was transferred quickly into a rectangle foam box which contain liquid nitrogen at a height of about $1 \mathrm{~cm}$, where the straws were exposed to nitrogen vapor for 8 minutes as follows: one minute at about $10 \mathrm{~cm}$ distance above the surface of the liquid nitrogen, 4 minutes at about $8 \mathrm{~cm}$ distance above the surface of the liquid nitrogen, 3 minutes at about $3 \mathrm{~cm}$ distance above the surface of the liquid nitrogen, then straws removed from the rack and dipped directly into the liquid nitrogen canister.

The period between semen extension and completion of semen freezing don't exceed 90 minutes as semen $\mathrm{pH}$ dose not became stable until 60-90 minute from the start of dilution.

\section{Examination of frozen-thawed semen:}

Frozen straws were thawed in a water bath at $37^{\circ} \mathrm{C}$ for 30 seconds ( $\mathrm{Si}$ et al. 2006).After thawing, semen samples were examined for percentage of progressive motility, dead and total abnormal spermatozoa.

\section{Artificial insemination:}

Females chosen for insemination were thought to be sexually receptive (had red color of vulva lips). In order to induce ovulation, females were injected intramuscularly with $0.3 \mathrm{ml}$ receptal (GnRH analogue, $1.26 \mu \mathrm{g}$ of busereline acetate; Intervet, Cairo, Egypt). Thawed diluted semen showed progressive motility less than $50 \%$ didn't use for AI. Then, each doe was inseminated artificially with $0.5 \mathrm{ml}$ diluted semen (containing approximately 30.26 million sperms) just after GnRH injection. Pregnancy was detected by trans-abdominal palpation 14 days post-insemination to determine pregnancy 
rate (PR). Litter size (LS) was determined for each doe directly after kindling.

\section{Statistical analysis:}

Analysis of variance was performed using SAS program (SAS, 2011) to test the significance of treatments using one way ANOVA. Differences among experimental groups were tested by Duncan's Multiple Range test (1955). The statistical model was:

$$
Y_{i j}=\mu+t_{i}+e_{i j}
$$

Where: $Y_{i j}$ is the observation of the studied trait of $j^{\text {th }}$ animal of $i^{\text {th }}$ treatment, $\mu$ is the overall mean, $t_{i}$ is the fixed effect of treatment $(I=1,2, \ldots \ldots), e_{i j}$ is the individual error.

For pregnancy rate trait, catmod and Chi-Square test for homogeneity of variance was performed using SAS program (SAS, 2011).

\section{RESULTS AND DISCUSSION}

\section{1- Physical semen characteristics of diluted NZW rabbits semen before and after freezing:}

The effect of RJ on some physical characteristics of diluted NZW rabbit semen before and after freezing are represented in Table 1. More than $88 \%$ of spermatozoa were found motile for semen extended with $10 \mathrm{mg} \mathrm{RJ} / 6 \mathrm{ml}$ diluent (equal to $1.67 \mathrm{mg} \mathrm{RJ} / 1 \mathrm{ml}$ diluents) vs $83 \%$ for $2 \%$ honey extender and $53 \%$ for the basal extender of Tris-citric-glucose-DMSO+ $20 \%$ egg yolk. The differences in percentage of progressive motility were significant at $\mathrm{P} \leq 0.05$ (Table, 1). Values of progressive motility after thawing for the eight extenders varied in a descending manner for the ascending concentrations of RJ. On the other hand, progressive motility before freezing showed unclear differences among the experimental groups, The RJ extenders showed higher values compared with both basal extender and $2 \%$ honey extender.

The higher concentrations of RJ more than $10 \mathrm{mg} / 6 \mathrm{ml}$ diluent did not sustain the motility of diluted rabbit semen after freezing suggesting that theeffect on sperm motility might be dependent on concentration. Abd-Allah (2012) suggested that treating buffalo sperm with $0.4 \%$ RJ in combination with heparin increased active motility of spermatozoa.

The current results showed that adding RJ to extenders may improve their capacity as a cryoprotectant for rabbit spermatozoa. The action mechanism of RJ effects on sustaining the improvement of spermatozoa 
ROYAL JELYY IN HONEY-INCLUDED EGG YOLK BASED EXTENDERSONRABBIT SPERM 
quality among a period of conservation in liquid nitrogen is unclear. Further experimentation in vitro and validation would be needed to prove any useful benefit and action mechanism of native RJ.

The impact of adding RJ to rabbit semen extenders was studied on viability and sperm abnormalities immediately after dilution and after thawing (Table, 1).Values obtained for both percentages of dead sperms and abnormalities immediately after dilution were low and the differences among experimental groups were lower for RJ extenders compared with those without RJ. However, adding honey to rabbit semen extenders decreased percentages of dead and abnormal spermatozoa after freezing and thawing. The differences were significant $(\mathrm{P} \leq 0.05)$ and may be concentration dependent. progressive motility, lower dead and lower abnormal spermatozoa compared to the other experimental groups. Therefore, based on the present results, the inclusion of RJ to honey-egg yolk based extenders was found to sustain both sperm motility and livability.

\section{2- Fertilizing ability of frozen NZW rabbit semen:}

The effect of RJ on fertilizing ability of frozen NZW rabbit semen are given in Table 1. The results obtained for pregnant females inseminated artificially with diluted semen of the seven previous groups after one month of conservation in liquid nitrogen were 12,16, 18, 15, 14, 13 and 11/20, respectively (Table, 1). Values of litter size were 5.8, 6.8, 7.4, 7.0, 6.0, 5.8 and 5.2 litters/doe, respectively. The differences between extenders in semen fertilizing ability were highly significant $(\mathrm{P} \leq 0.001)$. The better values for fertilizing ability parameters were for the concentration of $10 \mathrm{mg} \mathrm{RJ} / 6 \mathrm{ml}$ diluent. Abd-Allah (2012) studied the effect of RJ on fertilizing ability of buffalo spermatozoa in vitro, and suggested that treating buffalo semen with $0.4 \% \mathrm{RJ}$ in combination with heparin is effective not only to induce sperm acrosome reaction but also for in vitro fertilizing capacity of cryopreserved buffalo spermatozoa.

Cryopreservation induces sublethal damage to the spermatozoa, thereby reduce their fertile life (Mocé and Vincente, 2009). The present study revealed that addition of RJ to semen extenders may improve diluted rabbits semen characteristics in a dose dependent manner. The effects of RJ on spermatozoa quality and fertilizing capacity may be attributed to the effect of RJ containing motility stimulants such as adenosine and adenosine monophosphate (AMP) N (1)-oxide), which are already known to enhance the motility of sperm by an inhibiting cAMP at the level of the sperm tail and stimulated the phosphorylation 
of not only mitogen-activated protein kinase (MAPK) but also that cAMP/calcium - response element - binding protein (Vijayaraghavan and Hoskins, 1981; Parrish et al., 1988; Fraser and Duncan, 1993).

The results of the present study showed that addition of RJ to rabbits semen extenders improved sperm motility, viability and fertilizing ability of diluted rabbits semen stored frozen in liquid nitrogen and may improve cryopreservation of rabbits spermatozoa. These results showed that addition of RJ to honey-included egg yolk extenders could be used for the conservation of diluted rabbit semen using freezing techniques.

In conclusion, the results of the present study suggested that the addition of royal jelly in bee honey-included egg yolk based extenders improved the motility, viability and abnormalities of rabbit spermatozoa and may improve cryopreservation of rabbits spermatozoa. However, this effect is concentration dependent and higher concentrations of RJ have negative effect on semen quality or fertilizing ability. Further studies are needed and recommended for verifying the present results, particularly under summer hot conditions in Egypt.

\section{Acknowledgement}

The author would like to acknowledge the technical assistance of Mr. A.H. Khadr and A.S.S. Baky; Prof. Dr. Manal M.A. El-Sayed for her valuable help in statistical analysis; Captain Amro Zaied for providing female rabbits and Prof. Dr. A. Bassiouny for providing pure honey and royal jelly.

\section{REFERENCES}

Abd-Allah, S.M. (2012). Effect of royal jelly on the fertilizing ability of buffalo spermatozoa. J. Buffalo Sci., 1: 1-4.

Al-Sanafi, A.E.; S.A. Mohssin and S.M. Abdulla (2007). Effect of royal jelly on male infertility. Thi-Qar Med. J., 1 (1): 1-12.

Al-Waili, N.S. (2004). Investigating the antimicrobial activity of natural honey on the pathogenic bacterial infections of surgical wounds and conjuctiva. $J$. Med. Food, 7 (2): 210- 222.

Duncan, D.B. (1955). Multiple range and multiple F-test. Biometrics, 11: 1-42. Elnagar, S.A. (2010). Royal jelly counteracts bucks "summer infertility". Anim. Reprod. Sci., 121: 174-180. 
Elnagar, S.A.; O.A., Elghalid and A.M. Abd-Elhady (2010). Royal jelly: can it reduce physiological strain of growing rabbits under Egyptian summer conditions? Animal, 4(9): 1547-1552.

El-Sherbiny, A.M. (1987). Seasonal variations in seminal characteristics of rabbits. M. Sc. Thesis, Fac. of Agric., Ain Shams Univ., Cairo, Egypt.

Fraser, L.R. and A.E. Duncan (1993). Adenosine analogues. J. Reprod. Fertil.,: 187-194.

Gasic, S.; D. Vucevic; S. Vasilijic; M. Antunovic; I. Chinou and M. Colic (2007). Evaluation of the immunomodulatory activities of royal jelly components in vitro. Immunopharmacol.Immunotoxicol., 29: 521-536.

Graham, J. (1992). The Hive and Honey Bee. Dadant and Sons, Hamilton, Illinois, USA.

Hassan, A.A. (2009). Effect of royal jelly on sexual efficiency in adult male rats. Iraqi J. Vet. Sci., 23 (II): 155-160.

Holt, W.V. (2000). Basic aspects of frozen storage of semen. Anim. Reprod. Sci., 62: 3-22.

Kashiwazaki, N.; Y. Okuda; Y. Seita; S. Hisamata; S. Sonoki; M. Shino; T. Masaoka and T. Inomata (2006). Comparison of glycerol, lactamide, acetamide and dimethylsulfoxide as cryoprotectants of Japanese White Rabbit spermatozoa. J. Reprod. Dev., 52 (4):511-516.

Madhuri, D.; V.K. Gupta; S.P. Nema; A. Patidar; M. Shivhare; N. Singh and V. Shakya (2012). Modern semen evaluation techniques in domestic animals: a review. DHR Inter. J. Biomed. life Sci.,3 (1), 62-83.

Mărghitas, L.A. (2008). Produsele Apicole Şi Principalele Lor Însuşiri Terapeutice. In: Albinele şi produsele lor. L.A. Mărghitaş, second ed. Ceres, Bucharest, pp. 280-378. Based on Pavel et al. (2011).

Mocé, E. and J. S. Vicente (2009). Rabbit sperm cryopreservation. Anim. Reprod. Sci., 110(A review): 1-24.

Molan, P.C. and K.M. Russell(1988). Non-peroxide antibacterial activity in some New Zealand honeys. J. Apic. Res., 27 (1): 62-67.

NRC (1977). Nutrient Requirements Of Rabbits. 2nd Review Edition. National Academy of Science. USA. CA. 30 pp.

Parrish, J.J.; J.L. Susko-Pamsh; M.A. Winter and N.L. First(1988). Capacitation of bovine sperm by heparin. Biol. Reprod., 38: 1171-1180.

Pavel, C.I.; L.Al.Mărghitas; O. Bobiş; D.S. Dezmirean; A.Şapcaliu; I. Radio, and M.N. Mădaş (2011). Biological activities of royal jelly. Review. Anim. Sci. Biotechnol., 44 (2): 108 - 118. 
Safaa, H. M.; R. Lavara; M. P. Viudes-de-Castro; D. A. A. Elsayed; G. M. K. Mehaisen; F. Marco-Jiménez and J. S. Vicente (2012). Effect of different freezing extenders on semen quality, fertility and prolificacy in two selected lines of rabbit bucks.Proceedings 10th World Rabbit Congress Sharm El-Sheikh-Egypt. pp. 325-329.

SAS (2011). Base SAS 9.3 Procedure Guide: Statistical Procedure. Cary, NC, USA.

Si, W.; T. Hildebrandt; C. Reid; R. Krieg; W. Ji; M. Fassbender and R. Herms (2006). The successful double cryopreservation of rabbit (Oryctolaguscuniculus) semen in large volume using the directional freezing technique with reduced concentration of cryoprotectant. Theriogenology, 65: 788-798.

Smith, J.T.; D.T. Mayer and H.A. Herman (1954). A comparison of the ability of certain egg yolk diluents to maintain storage of bull semen. $J$. Dairy Sci., 38: 684. Based on Olayemi, F.O.; D.A. Adeniji and M.O. Oyeyemi (2011). Evaluation of sperm motility and viability in honeyincluded egg yolk based extenders. Global Veterinaria, 7 (1): 19-21.

Vijayaraghavan, S. and D. Hoskins (1981). Regulation of bovine sperm. Biol. Reprod., 34: 468-477.

Vincente, J.S. and M.P. Viudes-de-Castro (1996). A sucrose-DMSO extender for freezing rabbit semen. Reprod. Nutr. Dev., 36: 485-492.

Viudes-de-Castro, M.P. and J.S. Vicente (1996). A simple method for freezing rabbit semen with successful results on fertility and prolificity. Anim. Reprod. Sci., 44: 195-201.

Yang, A.; M. Zhou; L. Zang; G. Xie; H. Chen; Z. Liu, and W. Ma (2012). Influence of royal jelly on the reproductive function of puberty male rats. Food Chemi. Toxicol., 50: 1834-1840. 


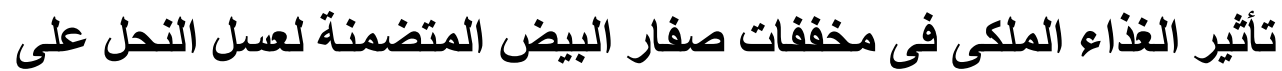

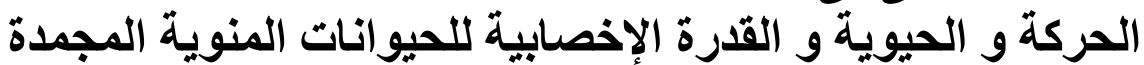
فى الأرانب

\author{
أحمد محمد الثربينى \\ قسم الإنتاج الحيوانى ـ كلية الزراعة ـ جامعة عين شمس - القاهرة - مصر.
}

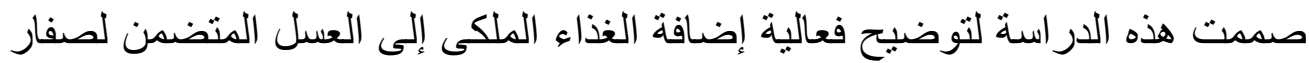

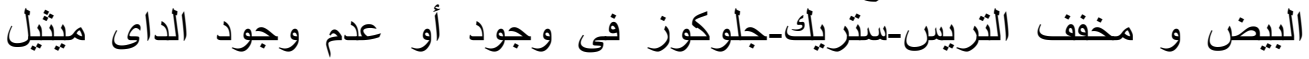

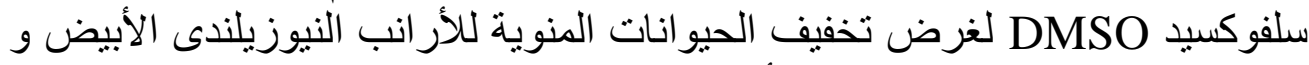

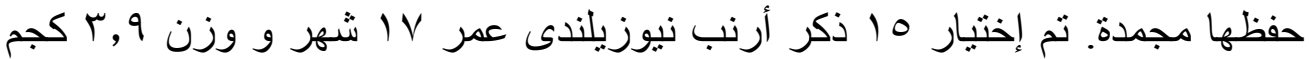

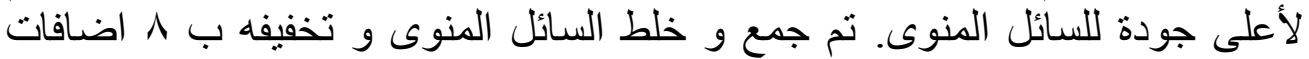

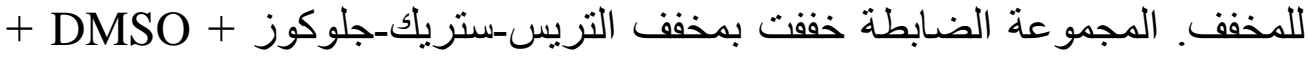

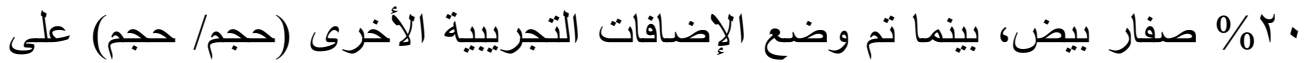

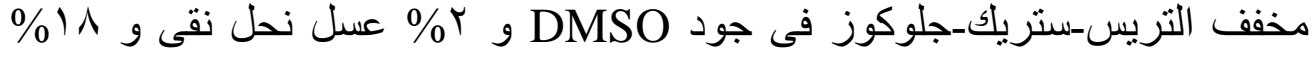

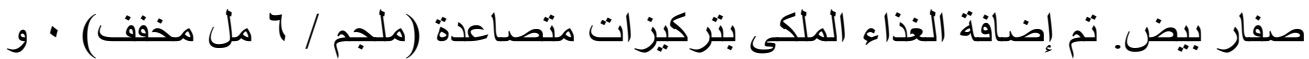

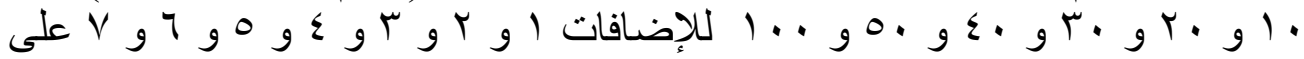

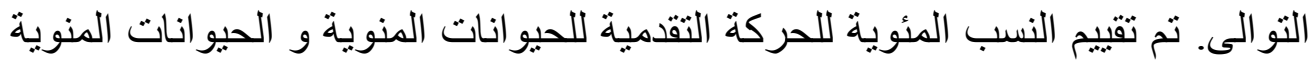

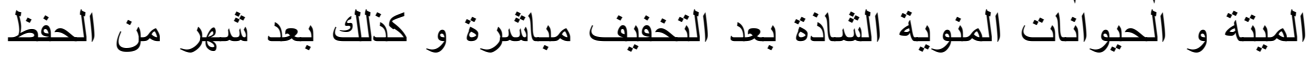

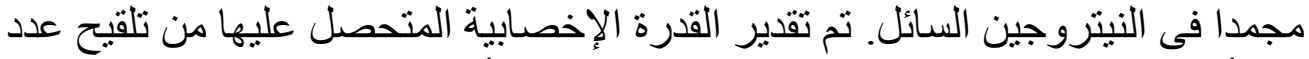

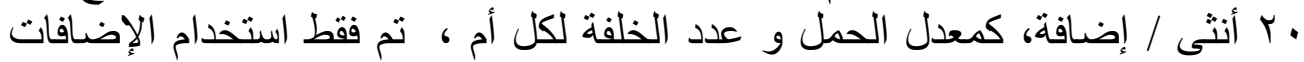

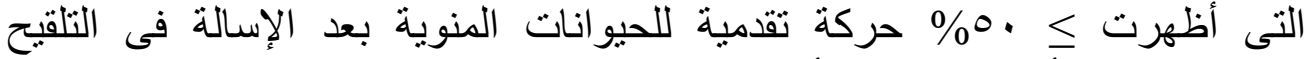

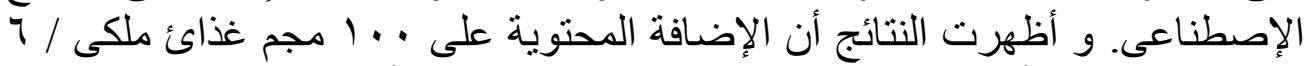

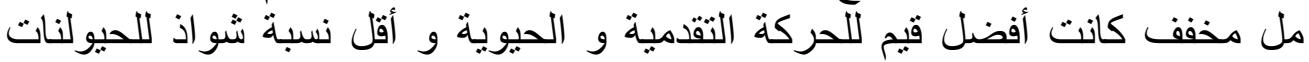

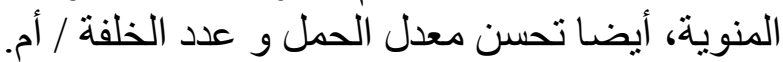

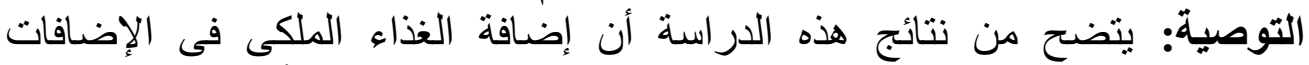

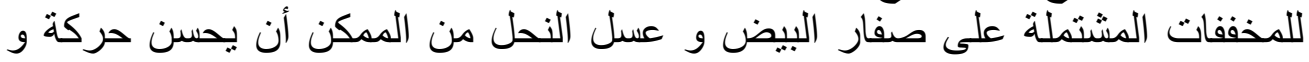

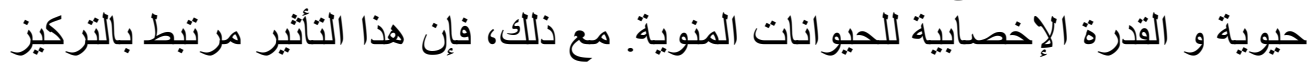

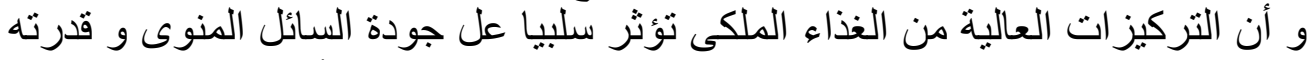
الإخصابية و قد تحسن عوامل الحفظ الحيوية للحيو النات الحئ المنوية للأر انب. 